\title{
Load-deformation behaviour of a deformable rockbolt and accessories under dynamic loading
}

\author{
FC Charette Normet Canada Ltd., Canada
}

AJ Hyett Yieldpoint Inc., Canada

B Voyzelle Natural Resources Canada, Minerals and Metals Sector, CanmetMINING, Canada

T Anderson Natural Resources Canada, Minerals and Metals Sector, CanmetMINING, Canada

\begin{abstract}
This paper presents the results of investigation into the capacity of a deformable support system (D-Bolt) to handle various types of dynamic events. Instrumented D-Bolts and plates were subjected to drop tests, providing insights into the effects of dynamic loading onto dynamically resistant bolting systems.

Strain measurements are taken during and after the impacts on the bolt. A correlation is drawn from the static performance of the components and their dynamic resilience. A discussion on the reaction of a support system to various forms of dynamic events is presented and suggestions on further requirements of dynamic support system are put forward. Comparison to design methods and support system calculation are offered. Suggestions on dynamic testing protocols are also offered.
\end{abstract}

\section{Introduction}

The D-Bolt (Figure 1) is a dynamically resistant rockbolt introduced in 2009 for ground support in high stress environments. Using high performance steel and an engineered configuration, the rockbolt provides high static strength and large displacement capacity to handle squeezing ground conditions as well as seismicity (Li 2010; Li \& Charette 2010; Charette \& Li 2011). The instrumented D-Bolt, equipped with displacement sensor digital technology (Charette \& Hyett 2013; Charette 2012; Spearing et al. 2012), is also intended to be used in squeezing ground conditions as well as in seismically active ground. However, no dynamic testing had been done on the product to thoroughly evaluate the behaviour of the strain measurement system while undergoing dynamic loading. Dynamic loading in the form of drop tests (Labrie et al. 2008) is a reproducible and consistent method of simulating rock burst effect on rock bolts; although it is not perfect in simulating the various parameters encountered with mining seismicity, the results can certainly be used as a comparative standard between various rock bolt types and make. Since they subject the bolt to various levels of impact energy, it is possible to evaluate the robustness of a given instrumentation method under violent dynamic loading.

The instrumented D-Bolt tested in the discussed laboratory test program is shown in Figure 2. It is a typical $2.4 \mathrm{~m}$ long, $20.5 \mathrm{~mm}$ diameter D-Bolt, with threads length of $125 \mathrm{~mm}$; the distance from the bolt head to the beginning of the first anchor area is $340 \mathrm{~mm}$. The D-Bolt is instrumented with Yieldpoint's displacement sensors technology; four out of six sensors are designed to handle deformation up to $2 \%$ total strain, while the two other sensors can handle over $5 \%$ of strain in the bar. This is much higher than conventional foil strain gauges. The last two sections of the bolts (S1 and S2) are instrumented and can be read digitally using a hand held readout unit or a datalogger (Yieldpoint 2011a, b), Figure 3. Since the sensors and wires are recessed in shallow slots cut diametrically along the length of the bolt (Figure 2), the instrumented bolt can be installed the same way as a regular rockbolt (Spearing et al. 2010). 


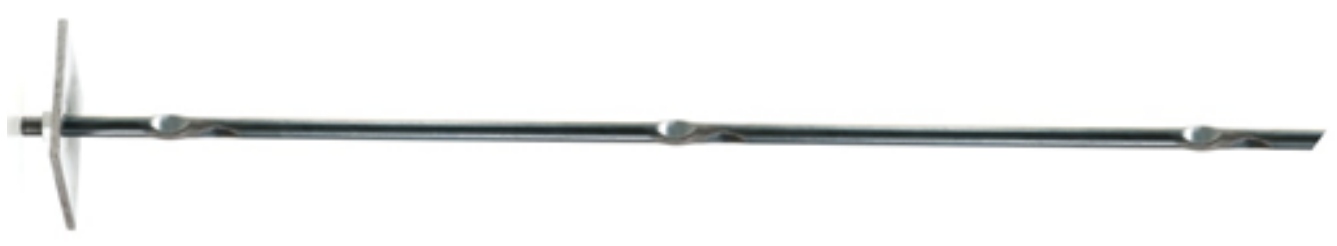

Figure 1 The D-Bolt rockbolt for high stress mining and tunnelling

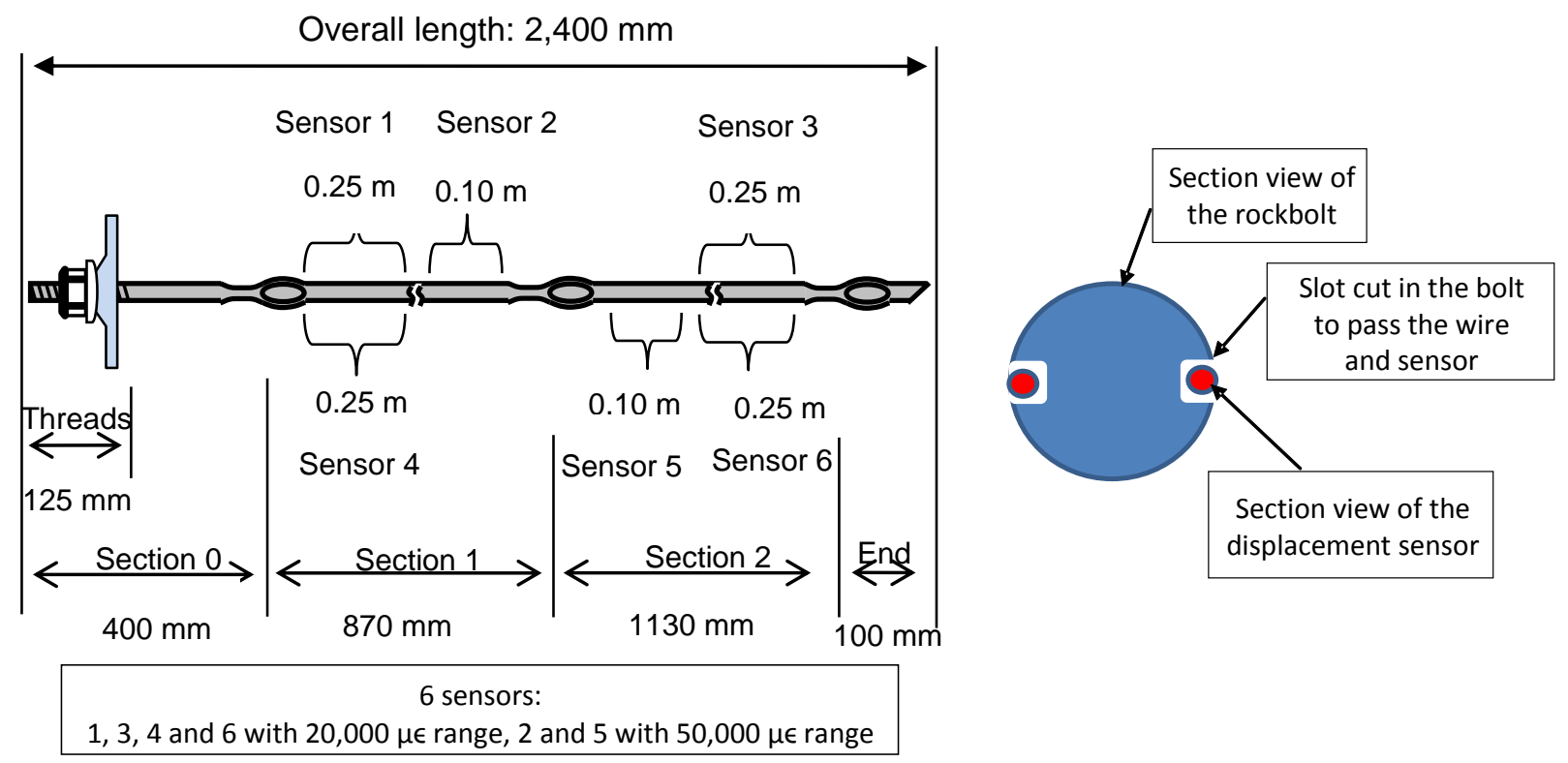

Figure 2 Schematic view of instrumented D-Bolt

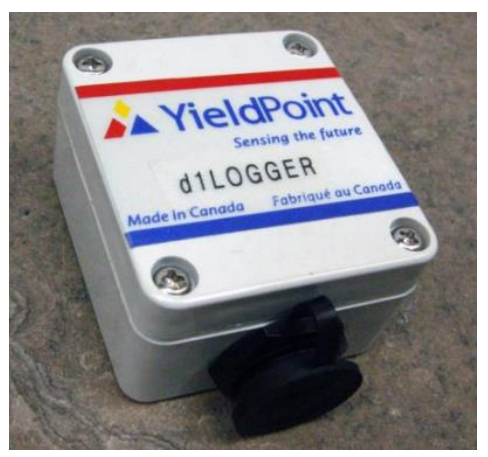

Figure 3 Datalogger used to record the instrument strain readings

\section{Tests description}

The investigation covered static and dynamic tests of $D$-Bolts and face plates used in the dynamic tests. The static tests on the bars were conducted with the system presented on Figure 4(a) (A and B). Tests on the plates were performed as shown on Figure 4(b). 


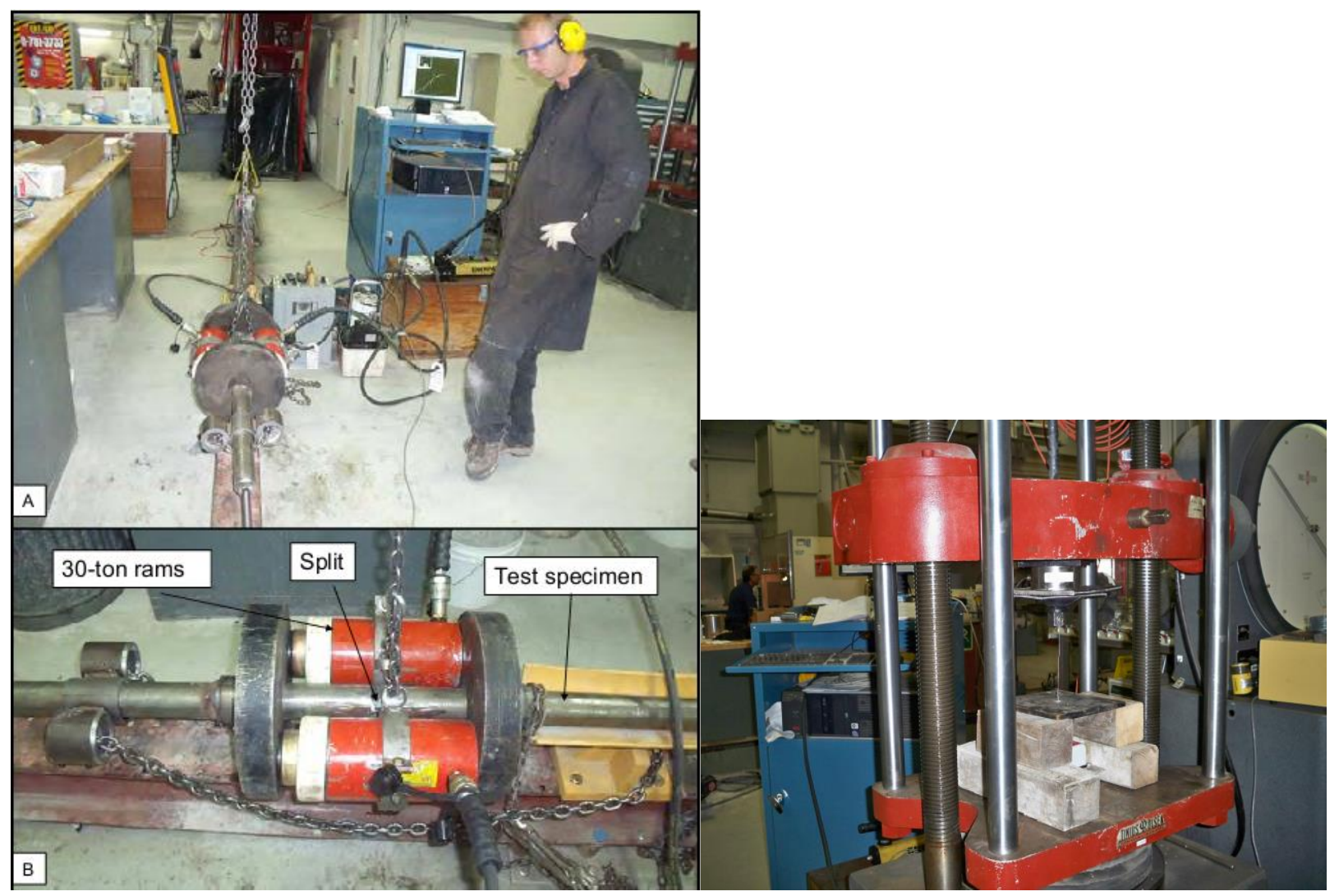

(a)

(b)

\section{Figure 4 Static tests set up; (a) for rockbolts; and (b) for face plates}

The dynamic testing was executed using the drop test rig of the CanmetMINING Laboratories in Ottawa (Figure 5(a)). Two types of drop tests were set up. The first set up was for continuous tube configuration with a non-instrumented D-Bolt (Figure $5(b)$ ), and the other for split tube configuration with instrumented D-Bolts (Figure 5(c)). The second set up was a continuous tube designed to impact the bolt on the head only, while the split tube is designed to hit between the anchors, simulating a large block of rock being ejected. All bolts were equipped with a $15.24 \times 15.24 \mathrm{~cm}(6 \times 6 \mathrm{in})$ dome plate. Some tests were conducted using a $110 \mathrm{kN}$ load capacity face plate with a $25 \mathrm{~mm}$ dome height, while another set of tests used a dynamic face plate with $200 \mathrm{kN}$ ultimate strength, and a dome height of $35 \mathrm{~mm}$ approximately.

The two series of drop tests with the instrumented bolt were done at low energy intervals, in order to encompass all the possible limitations in data monitoring and recording, and to establish an energy working limit for the instrument. 


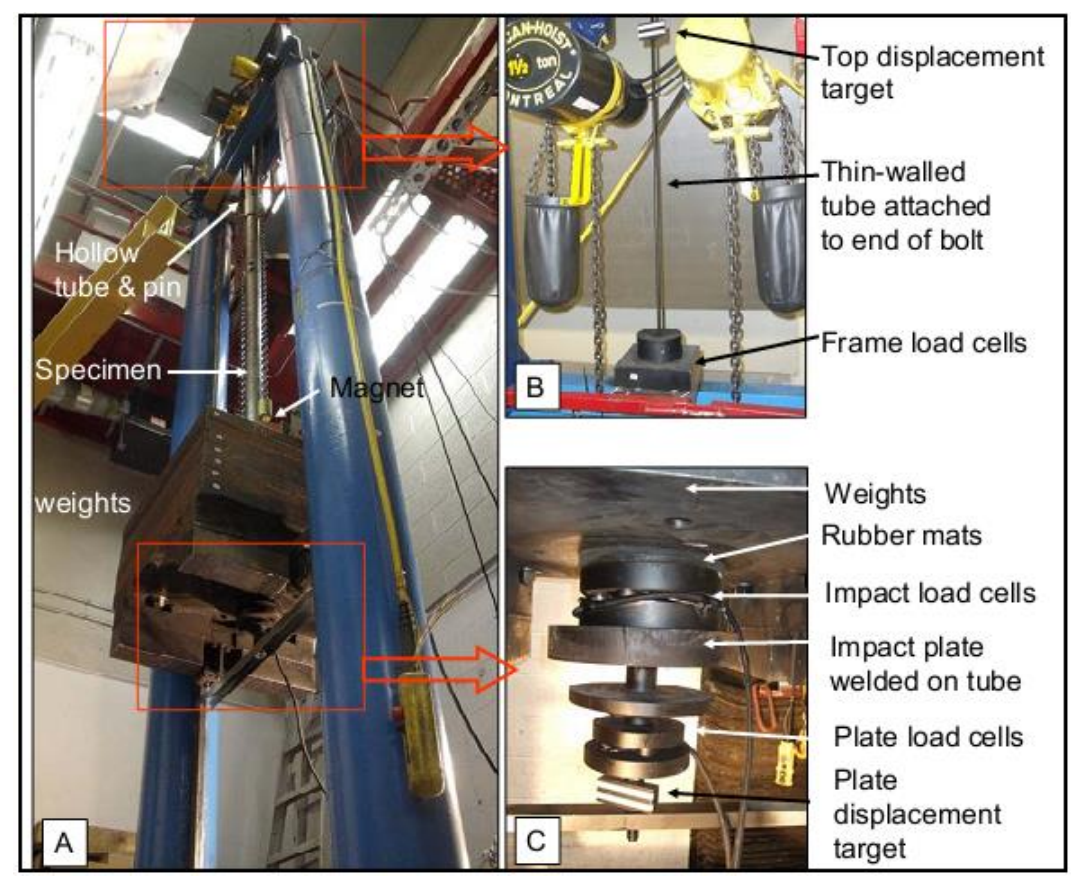

(a)

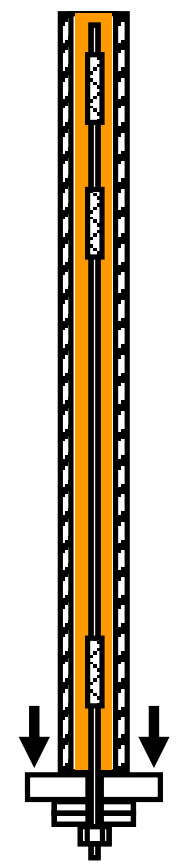

(b)

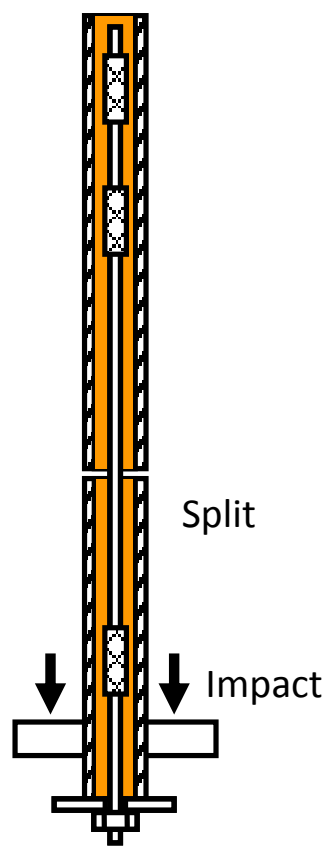

(c)

Figure 5 Configuration of the dynamic tests on D-Bolts; (a) Canmet testing rig; (b) continuous tube configuration; and (c) split tube configuration

\section{$3 \quad$ Results}

\subsection{Static testing}

Results for static testing conducted on D-Bolts are presented in Figure 6(a), for regular D-Bolts (22 mm as M1, M2 and M3, $20 \mathrm{~mm}$ as L1, L2 and L3), and in Figure 6(b) for an instrumented D-Bolt $20 \mathrm{~mm}$ with a typical load capacity of $190 \mathrm{kN}$. Figures $7(\mathrm{a})$ and (b) show static testing results for the face plates used for drop testing.

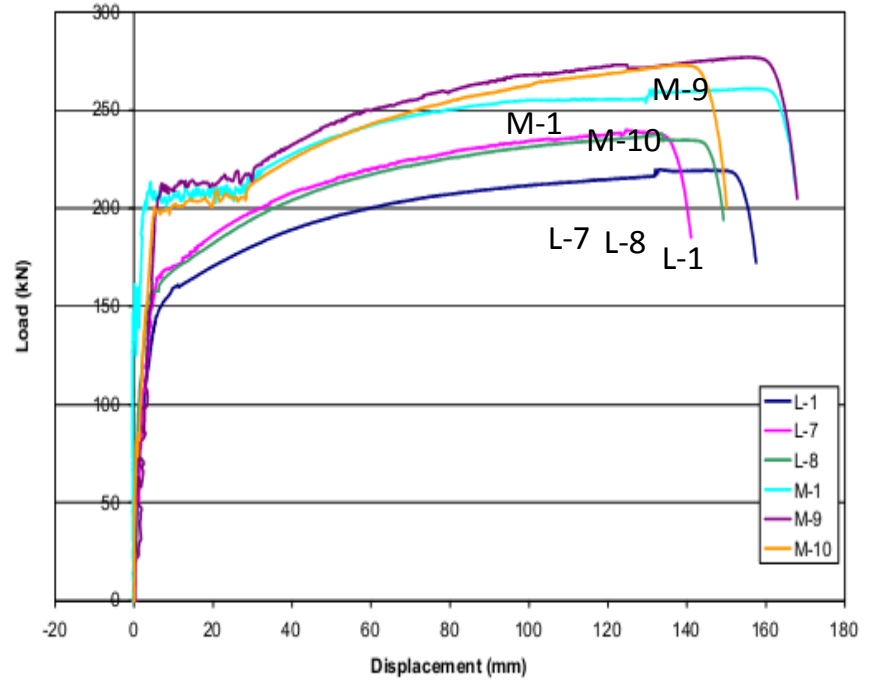

(a)

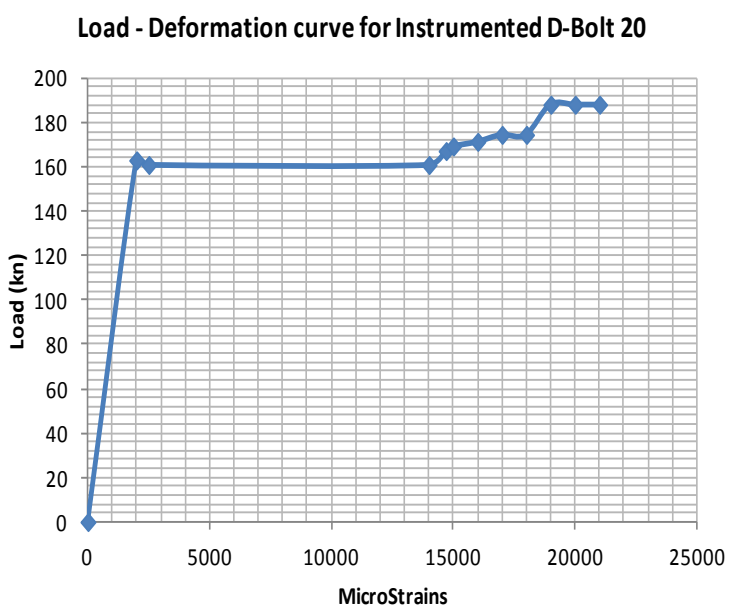

(b)

Figure 6Static pull tests on (a) regular D-Bolts (Doucet et al. 2010); and (b) an instrumented D-Bolt 
Static Load-Deformation for $110 \mathrm{kN}$ Domed Plates - Samples 1 and 2

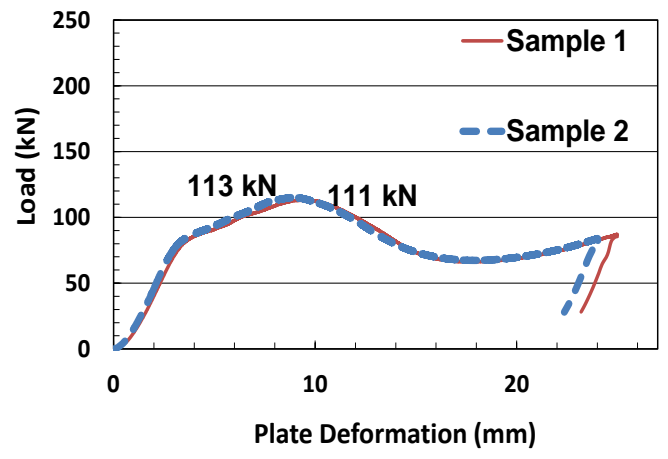

(a)
Static Load-Deformation curve for Dynamic Dome Plate

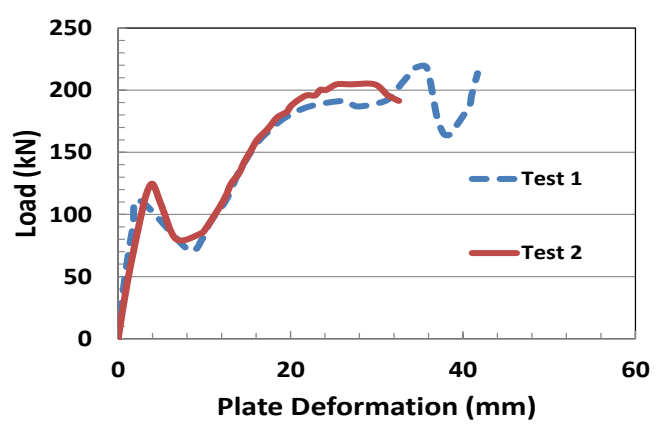

(b)

Figure 7 Static pull test on $150 \times 150 \mathrm{~mm}$ domed plate; (a) $110 \mathrm{kN}-25 \mathrm{~mm}$ domed plate; and b) $200 \mathrm{kN}-35 \mathrm{~mm}$ domed plate

\subsection{Dynamic testing - continuous tube}

Figure 8 shows the graphic results of the drop test with continuous tube conducted on a non-instrumented D-Bolt, with three loading steps of $5.26 \mathrm{~kJ}$ each, with a $200 \mathrm{kN}$ capacity dome face plate designed to absorb energy. At that energy level, it can be seen that the dome plate did the first damping process and as it started to flatten, the bolt head started to take load.

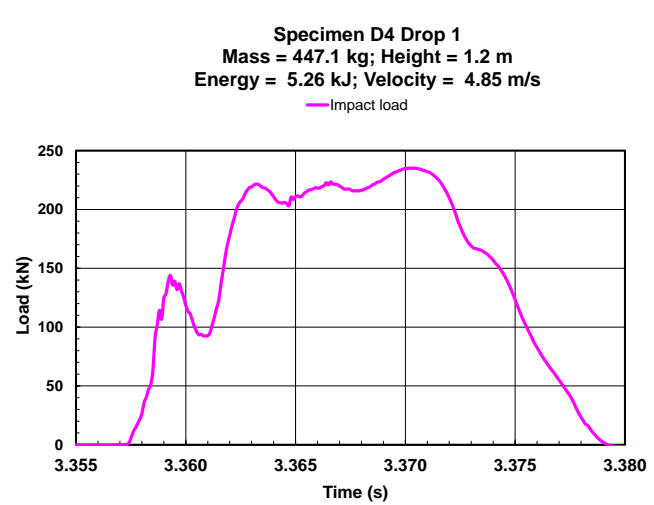

(a)

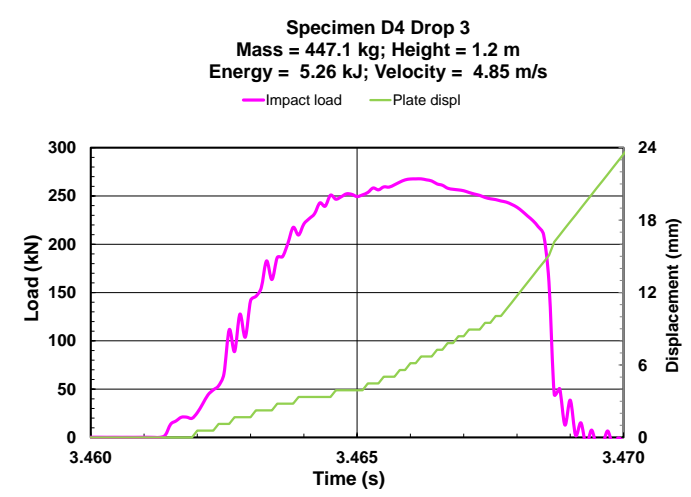

(c)

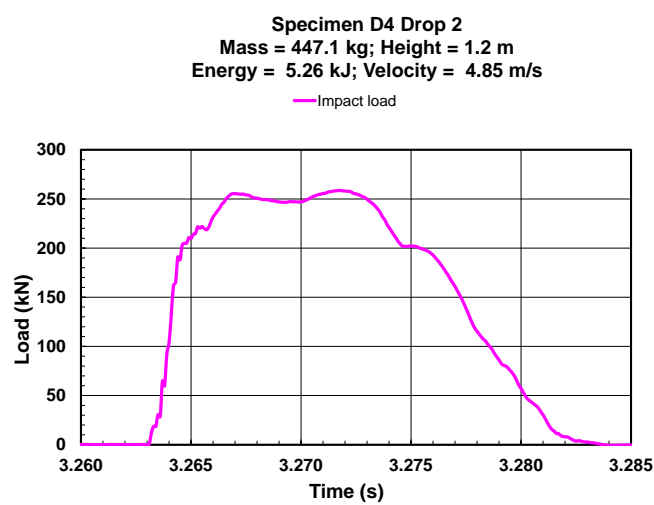

(b)

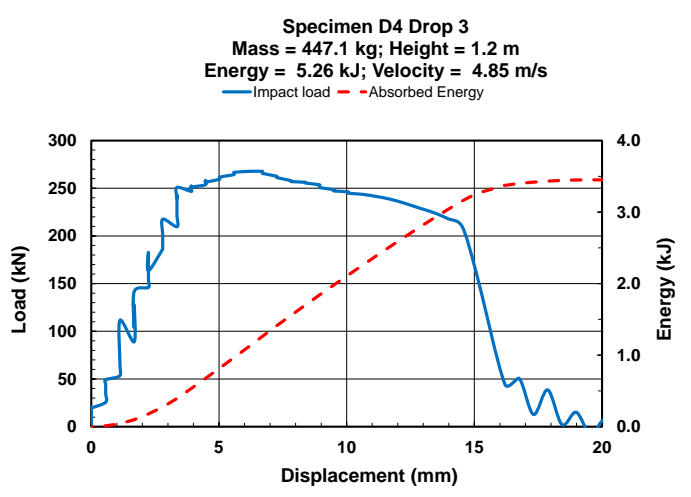

(d)

Figure 8 Results of continuous tube drop test on a non-instrumented D-Bolt head equipped with a $200 \mathrm{kN}$ face plate; (a) first drop at $5.26 \mathrm{~kJ}$; (b) second drop at $5.26 \mathrm{~kJ}$; (c) third and last drop at $5.26 \mathrm{~kJ}$; and (d) third drop and failure, with 


\section{$3.5 \mathrm{~kJ}$ of absorbed dynamic domed face plate after the third and final drop test on bolt}

The total energy absorbed by the system is $14 \mathrm{~kJ}$, two impacts at $5.26 \mathrm{~kJ}$ and a third one that failed at $3.5 \mathrm{~kJ}$. Typically, if the bolt was set with a stiff flat plate, the only elongation capability would lie with the threads area and the area before the anchor. From previous laboratory testing, it is expected that the bolt head can sustain a maximum of $45 \mathrm{~mm}$ of displacement at a load of $220 \mathrm{kN}$ for an energy of approximately $9 \mathrm{~kJ}$, so it is clear that the plate did provide a damping effect, even if it was not completely flattened (Figure 9). By contrast, an identical D-Bolt equipped with a softer $110 \mathrm{kN}$ capacity domed plate (Figure 10) does not absorb as much energy and fails at a single impact of $6.6 \mathrm{~kJ}$, with the plate flattening immediately and not offering much damping capacity.

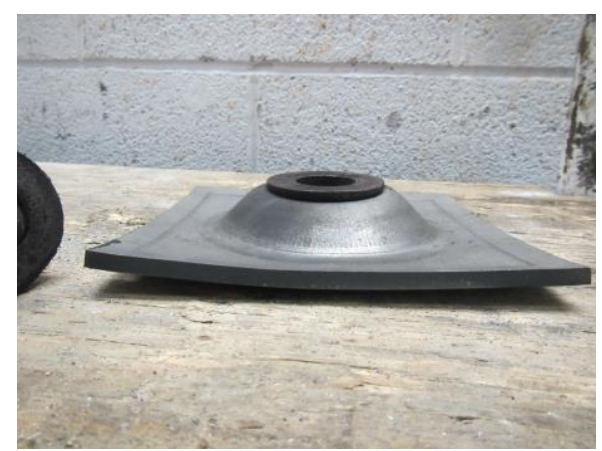

Figure 9 Dynamic domed face plate after the third and final drop test on bolt D4

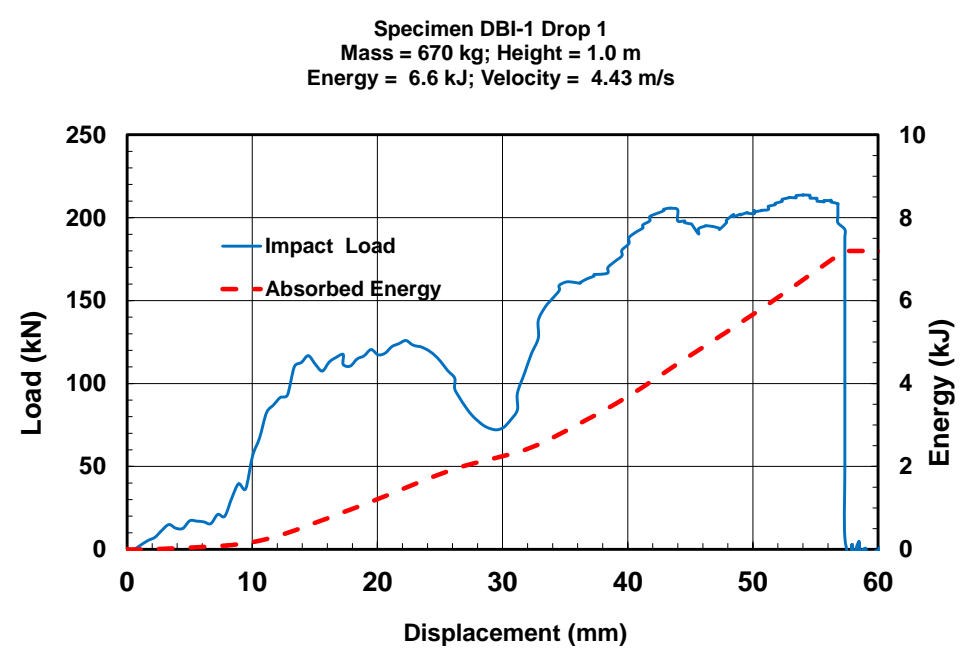
Figure 10 Result of continuous tube drop test with a D-Bolt equipped with a $110 \mathrm{kN}$
dome plate

\subsection{Dynamic testing - split tube}

Table 1 presents the results of two split tube drop testing sequences, conducted on instrumented D-Bolts. The first bolt (D2) was tested five times with an kinetic energy impact ranging from $2.1 \mathrm{~kJ}-6.6 \mathrm{~kJ}$, while the second bolt (D3) was tested a total of nine times with an impact energy ranging from 2.1-6.6 kJ too. Both bolts were set with $200 \mathrm{kN}$ dynamic dome plates. The displacement measurements of the sensors in the first section of the bolt (sensors 1,2 and 4) are calculated from the strain readings of the displacement sensors. The deformations from the displacement sensors are calculated using the strain value multiplied by the length of free bar in the area of the sensors. The calculation is specifically expressed for the Section 1 of the bolt as:

$$
\mathrm{D}=\varepsilon \times 870 / 1,000,000(\mathrm{~mm})
$$

Where: 
$\mathrm{D}=$ deformation of the free bar of Section 1 , in $\mathrm{mm}$.

$\varepsilon \quad=$ microstrain value.

Also found in Table 1 are the elongation values measured using the digital camera of the data acquisition system and rough measurements of the split with a measuring tape.

In general, good agreement is found between the measured values of elongation taken with the digital camera and the values calculated using the displacement sensors. Even in conditions of impact loading, the instrumentation is robust enough to function through the various hits, and provide a good estimate of the deformation of the bolt. Figure 11 presents two samples of data recorded during drop tests on bolts D2 and D3. The plate displacement refers to the reference plate used to measure the total opening of the split between the tubes (Figure 12), and not to the dome plate. To be noticed, even at very low kinetic energy, the initial load in the rockbolt reaches close to $200 \mathrm{kN}$, above the yield load of the D-Bolt $20 \mathrm{~mm}$, instrumented or not.

Table 1 Deformation measurements taken on Section 1 of the instrumented D-Bolts

\begin{tabular}{|c|c|c|c|c|c|c|c|c|}
\hline $\begin{array}{c}\text { Bolt } \\
\#\end{array}$ & $\begin{array}{c}\text { Drop } \\
\#\end{array}$ & $\begin{array}{c}\text { Kinetic } \\
\text { Energy } \\
\text { (kJ) }\end{array}$ & $\begin{array}{c}\text { Velocity } \\
(\mathrm{m} / \mathrm{s})\end{array}$ & $\begin{array}{l}\text { Split } \\
\text { (mm) }\end{array}$ & $\begin{array}{c}\text { Elongation } \\
\text { from } \\
\text { camera } \\
(\mathrm{mm})\end{array}$ & $\begin{array}{c}\text { Sensors } \\
1-4 / 2 \\
\text { average } \\
(\mathrm{mm})\end{array}$ & Failure & Comment \\
\hline D2 & 1 & 2.2 & 3.2 & 3.5 & 3.0 & & $N$ & \\
\hline D2 & 2 & 3.3 & 3.8 & 12 & 8 & 4.3 & $\mathrm{~N}$ & \\
\hline D2 & 3 & 4.4 & 4.4 & 23.5 & 22 & 14.5 & $\mathrm{~N}$ & \\
\hline D2 & 4 & 4.4 & 4.4 & 30 & 26 & 23 & $N$ & \\
\hline D2 & 5 & 6.6 & 5.2 & 43 & 39 & & $\mathrm{~N}$ & \\
\hline D3 & 1 & 2.2 & 3.2 & 4 & 3 & .01 & $\mathrm{~N}$ & \\
\hline D3 & 2 & 3.3 & 3.8 & 11 & 14 & 7.5 & $\mathrm{~N}$ & \\
\hline D3 & 3 & 4.4 & 4.4 & 23 & 24.5 & 16.5 & $N$ & $\begin{array}{c}\text { S1 } \\
\text { reached } \\
\text { limit }\end{array}$ \\
\hline D3 & 4 & 4.4 & 4.4 & 32 & 32.5 & 22.4 & $\mathrm{~N}$ & $\begin{array}{c}\text { S1, S4 } \\
\text { reach } \\
\text { limit }\end{array}$ \\
\hline D3 & 5 & 6.6 & 5.4 & 50 & 45.5 & 33.6 & $N$ & \\
\hline D3 & 6 & 4.4 & 4.4 & 60 & 56.5 & 42.4 & $\mathrm{~N}$ & \\
\hline D3 & 7 & 4.4 & 4.4 & 64 & 62.5 & & $\mathrm{~N}$ & \\
\hline D3 & 8 & 4.4 & 4.4 & 73 & 68.5 & & $\mathrm{~N}$ & \\
\hline D3 & 9 & 4.4 & 4.4 & 82 & & & $\mathrm{~N}$ & \\
\hline
\end{tabular}



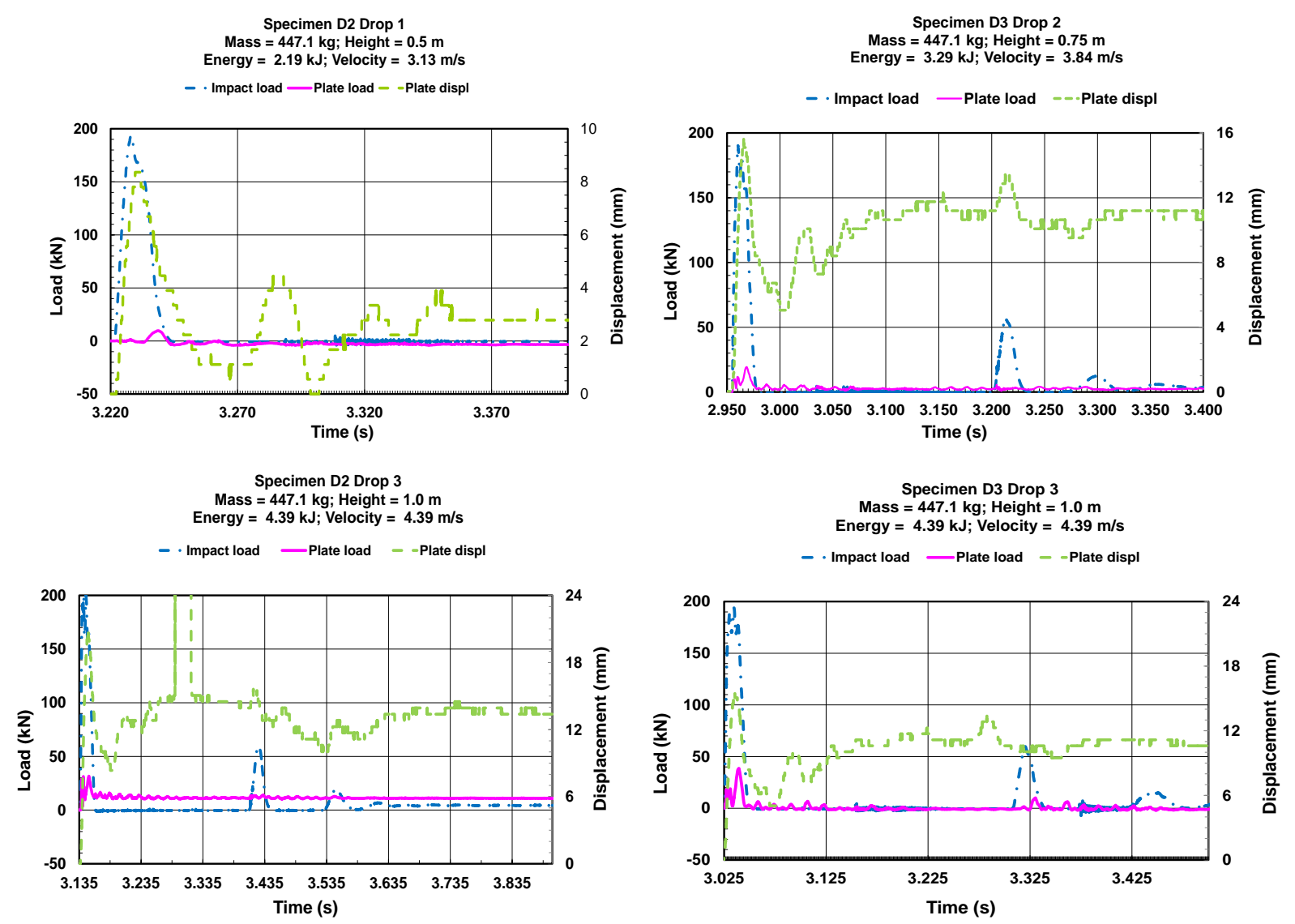

(a)

(b)

Figure 11 Samples of load and displacement measurement during drop tests for bolts D2 and D3, in a split tube configuration

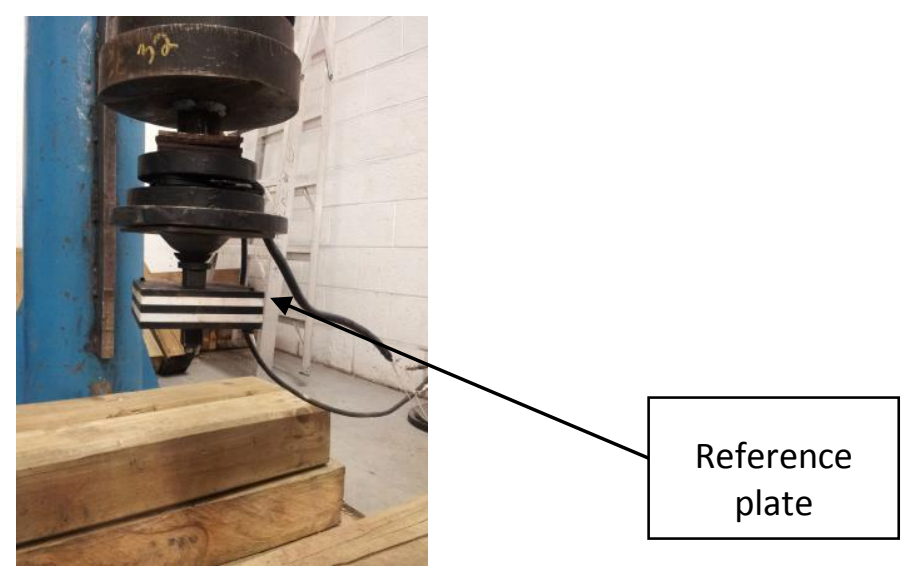

Figure 12 Configuration of the continuous tube set up with the load cell and reference plate 

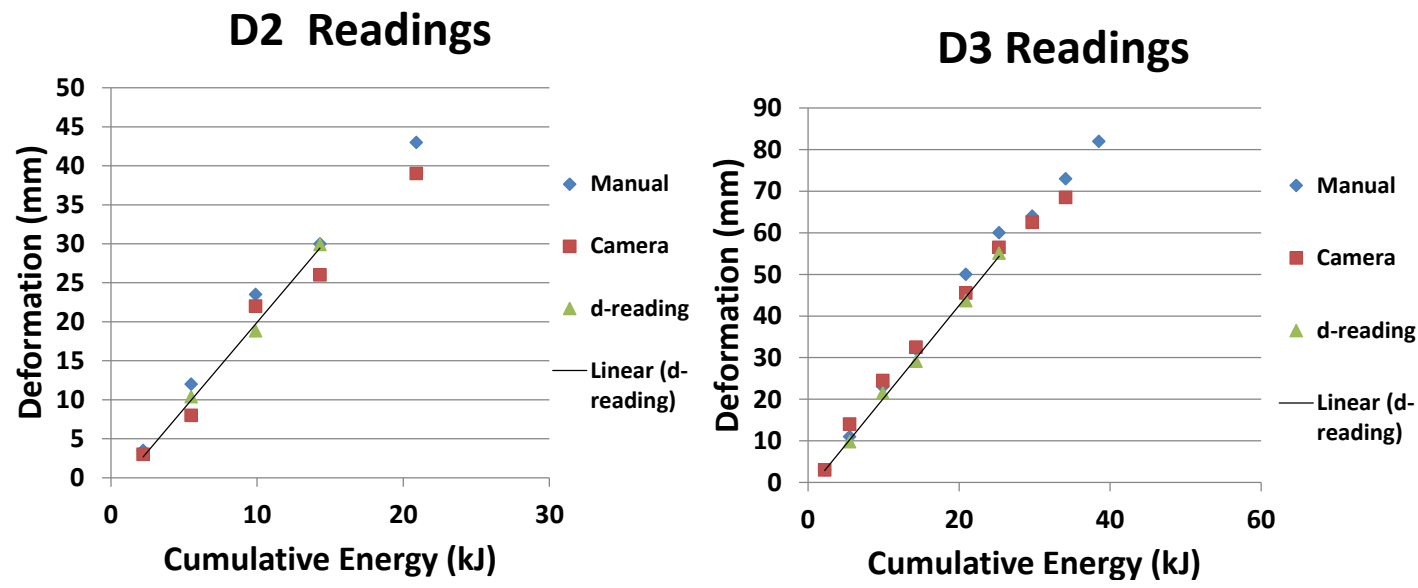

\section{Figure 13 Results of split tube drop tests on bolts D2 and D3 equipped with a 200 kN dome plate}

\section{Discussion}

The D-Bolt has proven to be very effective in squeezing ground conditions and field monitoring is on-going in several mines in Ontario, Canada. The high static capacity, combined with large elongation properties, provide the D-Bolt with the means to control the ground in large deformations conditions. The bolt is also used in seismically active mines, and the possibility to measure the deformations of the bolt in those conditions was considered to be the logical suite to the yielding ground conditions application. The instrumented D-Bolt, in its present form, can handle multiple dynamic impacts and still provide meaningful readings of the deformation along the bar between the anchors. The results of the three measurement methods used during the tests are similar, and suggest that the instrument provides meaningful data on the dynamic loading on the rockbolt.

The static tests results on the domed plates illustrates the difference between the static energy reserve of the two different plates; while the weaker plate should be able to dissipate $2 \mathrm{~kJ}$, the stronger has the ability to deliver almost $5 \mathrm{~kJ}$. However, the mechanism of energy damping is more complex and is linked to the load balance between the plate and the threads and bar. If the plate is too soft, it basically fails to work in tandem with the threads and only slightly reduce the momentum of the mass and give only more time to the mass to accelerate. By contrast, a plate that has a yielding point balanced with the yielding load of the bolt acts as a primary damping accessories, and reduces the impact energy on the bolt, making the bolt able to resist more efforts. This is obvious in the performance difference between the bolt with a $200 \mathrm{kN}$ face plate (Figure 8) which failed at $14 \mathrm{~kJ}$, and the bolt with a $110 \mathrm{kN}$ face plate (Figure 10) that failed at $7 \mathrm{~kJ}$ with no positive action from the face plate.

Performing drop tests on the head of the bolt as well as on the middle enables us to get a glimpse of the support reaction to different types of dynamic events. Concentrating the impact on the head of the bolt can be likened to a strain burst in massive rock, located at the periphery or the skin of the excavation. On the other hand, with an impact pulling out a joint located between the first and second anchor can be similar to a deeper strain burst, or an ejection following a fault slip event. Conducting the two types of tests is necessary to evaluate the overall performance of the rockbolt and its ability to secure an underground excavation under high stress conditions. Moreover, the plate used in the field needs to be part of the drop testing procedure. Doing so will provide a better understanding of the energy dissipation of the system, and provide insight into prospective improvements. Mesh should also be part of the system tested, and at the moment very few testing protocols are available to include the whole system in a dynamic test.

The impact on ground support design due to the new data is significant. First, it indicates the importance of having a ductile support system that is balanced, with the stiffness and strength of its various constituent being in a similar realm. Second, it shows that the energy damping of the system can be lessened by accessories that are too weak; ductility is good after high strength, but not necessarily before. Third, it 
shows that a dynamically designed accessory, like the face plate, can help the support tendon to work to the limit of its capacity instead of failing early; as such, care should be taken to use the proper accessory to adequately complement the tendon.

\section{Conclusion}

The instrumented D-Bolt can tolerate multiple dynamic impacts and provide meaningful readings of the deformation along the bar between the anchors. The investigation proved that individual impacts of almost $7 \mathrm{~kJ}$ do not affect the performance of the instrument, and the sensors limitation seems to be their designed elongation range.

The performance of the rockbolt is partly influenced by the mechanical behaviour of the face plate and the selection of the right face plate will enhance the performance of the fixture. While the application of sudden load between the anchors will be handled easily by the free bar length, any phenomenon that creates a localised loading in the threads area will be handled by the plate-threads tandem system. A strong energy damping plate will provide the best performance for supporting the ground.

A logical next step would be to see how the instrumented bolt performs during a field dynamic test, like a blasting test. Since a few bolts have been installed in seismically active locations, its field capability may very well be revealed in a near future.

Finally, the instrumented bolt will be installed in more squeezing ground conditions in 2014 and 2015 and a more complete understanding of the instruments performance and the bolt behaviour should result of the squeezing and seismic applications.

\section{References}

Charette, F 2012, 'Monitoring of dynamic bolts for high stress mining', in C Hawkes (ed.), Proceedings of the 21st Canadian Rock Mechanics Symposium: RockEng 2012, Canadian Rock Mechanics Association, pp. 71-78.

Charette, F \& Hyett, AJ 2013, 'Monitoring of dynamic energy resistant rockbolts: laboratory and field results', Proceedings of the 23rd World Mining Congress, Canadian Institute of Mining, Metallurgy and Petroleum, Westmount.

Charette, F \& Li, CL 2011, 'Innovative Engineering Approach to the Stabilisation of Rock Masses in High Stress Conditions', Proceedings of the CIM Conference and Exhibition 2011, Canadian Institute of Mining, Metallurgy and Petroleum, Westmount.

Doucet, C \& Anderson, T 2010, Laboratory testing of D-Bolts, CANMET-MMSL Report 10-043 (CR) Project 603828-00-0, Canada Centre for Mineral and Energy Technology, Ottawa.

Labrie, D, Doucet, C \& Plouffe, M 2008, Design guidelines for the dynamic behaviour of ground support tendons: Phase 1, Technical information data sheets, CANMET-MMSL Report 08-008 (TR), Canada Centre for Mineral and Energy Technology, Ottawa.

$\mathrm{Li}, \mathrm{CL}$ 2010, 'A new energy-absorbing bolt for rock support in high stress rock masses', International Journal of Rock Mechanics and Mining Sciences, vol. 47 pp. 396-404.

Li, CL \& Charette, F 2010, 'Dynamic performance of the D-Bolt', in M van Sint Jan \& Y Potvin (eds), Proceedings of the Fifth International Seminar on Deep and High Stress Mining, Australian Centre for Geomechanics, Perth, pp. 321-328.

Spearing, AJS, Hyett, AJ \& Kostecki, T 2012, 'New technology for measuring the in situ performance of rock bolts', in A Bobet (ed.), Proceedings of the 46th U.S. Rock Mechanics Symposium, American Rock Mechanics Association, Alexandria, paper 12-497.

YieldPoint Inc. 2011a, dLogger Specifications Sheet, YieldPoint Inc., Kingston.

YieldPoint Inc. 2011b, dReader Specifications Sheet, YieldPoint Inc., Kingston. 